\section{Canadian Light Source is ready to glow as final grant comes in}

[MONTREAL] A grant from the Canada Foundation for Innovation (CFI) has provided the final funding needed to start building a Can $\$ 173.5$ million (US\$ million) national synchrotron at the University of Saskatchewan. The machine will be called the Canadian Light Source (CLS).

According to Dennis Skopik, director of the university's Saskatchewan Accelerator Laboratory (SAL), this is the largest investment in scientific infrastructure in Canada within a generation.

The CLS will consist of an electron accelerator and storage ring that will emit electromagnetic radiation ranging from wavelengths in the infrared up to hard Xrays, providing a research tool for a wide range of disciplines. "That's why it is a very useful tool," says Skopik. "You dial in the wavelength you want and you've got it with more intensity than with any other synchrotron facility in the world."

It will be a third-generation synchrotron, of which only a handful currently exist. The decision to fund it was taken after major facilities in Europe and the United States reportedly threatened to restrict Canadians' access unless Canada developed its own.

Skopik says the decision has to some extent corrected the situation of science funding of several years ago, when major cuts were made. But he emphasizes that there was fierce competition for the funds.

"It's an extremely good step forward for Canada," he says. "It touches fields from physics to earth sciences, medical applications - just about any science and engineering is going to benefit. I don't know of any facility that has this broad range of uses."

Of the cost, Can\$140.9 million will be paid in cash and Can\$32.6 million in kind, including three University of Western Ontario beam lines which will be moved from the Aladdin facility in Wisconsin.

CFI's Can\$56.4 million contribution constitutes 40 per cent of the capital costs. The remainder will be covered by other federal departments, the Saskatchewan government, the city, Saskatchewan Power Corporation and the universities of Alberta and Western Ontario. Can\$19 million will come from other provinces, universities and industry to build beam lines.

The federal government will pay about 55 per cent of the Can\$13.9 million annual operating costs through agencies such as the research-granting councils. The rest will be covered by other sources, including users' fees and the university itself. Building will begin within two months, and the facility is due to open in 2003.

David Spurgeon

\title{
South African funding body faces evaluation headache
}

[CAPE TOWN] South Africa's National Research Foundation (NRF) was officially established on 1 April. It creates a single funding agency covering all research except clinical medicine at the country's universities, technikons (polytechnics) and museums.

The new organization combines the role of the old Foundation for Research Development (FRD) with the grant-giving functions of the Human Sciences Research Council, which still exists to administer its own inhouse research programmes.

Members of the NRF council were announced on 30 March by Ben Ngubane, the re-appointed Minister of Arts, Culture, Science and Technology. It will be chaired by psychologist M. F. Ramashala, vice-chancellor of the University of Durban-Westville.

Khotso Mokhele, the former president of the FRD, will act as interim chief executive officer until the council appoints a head, although he is widely regarded as the frontrunner for the post.

Research support will be handled by four divisions of the NRF: natural science and engineering; humanities and social sciences; environmental and agricultural sciences; and health sciences. The health sciences division is relatively small, as the NRF only pays for fundamental research in this area; clinical research is covered by the Medical Research Council, which remains autonomous.
A fifth division consists of the national research facilities that were previously part of the FRD: the SA Astronomical Observatory, the National Accelerator Centre, the Hartebeeshoek Radio-Astronomy Observatory and the J. L. B. Smith Institute of Ichthyology.

One of the government's aims in creating the foundation is to open up new opportunities for collaboration between the natural and social sciences, as it is in favour of interdisciplinary research. But the NRF faces the difficult task of integrating two very different mechanisms for evaluating research proposals in these disciplines.

The FRD has had a complex evaluation mechanism. A major component has been the individual rating of scientists by peer review. This has required that all scientists wishing to apply for funding are personally evaluated every five years, in addition to applying annually for research grants for the following year.

In contrast, research in the social sciences has been based primarily on project evaluation. Social scientists do not seem enthusiastic about the FRD evaluation system, though Mokhele described it last month as "the envy of research communities worldwide".

Mokhele sees the current funding mechanisms as remaining in place until the end of next year, when the FRD's current set of research programmes end.

MichaelCherry

\section{Britain promises cash for UK/SA joint research}

[CAPE TOWN] Britain's science minister, Lord Sainsbury, announced during a visit to South Africa last week that the UK government will contribute a further $£ 100,000$ (US $\$ 165,000)$ to a bilateral research fund, extending its activities for a further year.

The UK/South Africa Science and Technology Joint Research Fund, to which the South African government makes an equal contribution, was set up in 1996 to support projects in agriculture, biotechnology and biomedical and environmental science.

At a review of the fund's first three years of operation, held in Cape Town, Sainsbury applauded its success, saying that it has "reaped considerable benefits for science in both South Africa and the UK".

Sainsbury announced that a memorandum of understanding will be signed between the United Kingdom's Royal Society and South Africa's new National Research Foundation (NRF;see above) to build research capacity at historically black institutions.

Since September 1996, the Royal Society has provided $£ 250,000$ a year to establish centres of excellence at historically black universities - in biotechnology and marine biology at the University of the Western Cape, chemistry at the University of Zululand, stock science at the University of Fort Hare and computational modelling for materials science at the University of the North.

A collaborative scheme between the NRF and the Royal Society provides funds for exchange visits between these universities and counterpart institutions in the United Kingdom, and for replacement salaries for South African staff members upgrading their qualifications in the United Kingdom.

The historically black universities have seen drastic reductions in enrolment over the past five years (see Nature 398, 277; 1999). But Prins Nevhutalu, who coordinates the scheme at the NRF, feels this should not have a negative effect on attracting postgraduate students to a research centre of excellence. M.c. 